\title{
How can simulation help in supply chain development?
}

\author{
J-M Lehtonen, J. Holmström \\ Helsinki University of Technology, TAI Research institute \\ P.O. Box 9500 FIN-02015 TKK, Finland, + 3589451 1, + 358 \\ 94513665 ,jmlehto@tuta.hut.fi, jan.holmstrom@hut.fi
}

\begin{abstract}
The objective of this paper is to explore how simulation can be applied to support the development of responsive supply chains. We propose a stepwise approach for the use of simulation to support in evaluating appropriate supply chain designs. The role of simulation in the development process is a tool for evaluating and finding solutions when reconsidering the chain strategy. A basic materials manufacturer case is presented to give an application example. The use of simulation is also discussed from a knowledge management perspective. It is concluded that the integration of simulation models to existing ERP systems will help supply chain development especially for the responsive chains.
\end{abstract}

Supply chain, simulation, ERP

\section{Keywords}

\section{INTRODUCTION}

According to Fisher (1997) a responsive supply chain is required in a business environment that is characterised by short product life cycles, volatile demand patterns, recurring stock-outs and high contribution margins accompanied with rapid price erosion. In order to be responsive a company must be able to manage, not just the present demand and supply chain, but also the foreseen as well as unforeseen changes in the market. The tools and skills developed for running a cost-efficient supply chain are not enough, and sometimes not even applicable for developing responsiveness. What is of strategic importance is to have the skills and tools to support both the design of the demand-supply chains in fast changing environments as well as the accompanying general control principles for running and re-balancing the operation. 
In this paper the use of simulation in the supply chain development is studied. "Simulation is a numerical technique for conducting experiments on a digital computer, which involves certain types of mathematical and logical models that describe the behaviour of a system over extended periods of real time" (Naylor et al., 1966). Simulation is further restricted to discrete event simulation, as the single events in distribution and discrete parts manufacturing can be modelled by using discrete techniques. The key advantage of discrete event simulation modelling over analytical models according to Hoover \& Perry (1989) is that you can include much richer detail and still obtain results. In comparison to the real system, the researcher has control over the other variables (Johnsson, 1992) and non-existent systems can also be studied (Hoover \& Perry, 1989).

The objective of this paper is to explore how simulation can be used to support the development of a responsive supply chain. We will first present an approach for applying simulation to supply chain development, and then with the help of a case study outline the type of decision making for which simulation is most useful. Finally, we will consider the practical opportunities to incorporate simulation as a component in the operational toolbox of a company pursuing a responsive supply chain strategy.

\section{SIMULATION APPROACH FOR SUPPORTING A RESPONSIVE SUPPLY CHAIN STRATEGY}

A simulation approach for supporting the supply chain strategy of a company needs to address three basic issues. Firstly, what is the appropriate basic strategy for the supply chain? Secondly, what are the design options for realising the strategy. And finally, on a more detailed level, how should the company run and balance its chain?

For the first point, the basic supply chain strategy choice is between a responsive and an efficient supply chain. Simulation is used as an approach to support in the design decisions. Through simulation the economics of different logistics configurations can be uncovered, i.e. what is the importance and impact of different demand-supply chain parameters on the company performance. On the tactical and operational levels simulation can be applied to support the running and re-balancing of the demand-supply chain. Through 'what if' analysis in connection with product introductions the company can determine what products to supply in a 'responsive' mode to minimise mark-downs and lost sales. A good example of applying simulation in finding the right supply chain for key products and customers can be found in Waller (1999) where simulation is used to determine the impact of implementing VMI solutions with key customers on the capacity and service level for a consumer goods producer.

There exists a number of simulation project models in literature that are in close agreement and an interested reader can refer to Hoover and Perry (1989), Law and Kelton (1991) or Robinson )1994). In the context of supply chain development the most crucial steps of a simulation model building are problem formulation and data 
gathering and analysis. These steps have received little attention. However, Lehtonen and Seppälä (1997) introduce a methodology for data gathering and analysis in a simulation modelling project that is based on the Controllability Analysis work by Eloranta and Räisänen (1984). First the abundance of data is analysed and reduced by applying Controllability Analysis (CA) for the purpose of simulation modelling. The reduction of effort comes from three sources: reduced coding while CA helps identifying key problem areas, reduced input data needs while minor detail can be replaced by approximations and reduced experimental designs while in the course of CA improvement ideas regularly surface.

Our stepwise approach takes as a starting point the business environment of the company and proceeds to scenarios for evaluating solution tactics and focused modelling to identify operative solutions.

\section{Step 1: Identify appropriate supply chain strategies}

The first step in the supply chain development is an assessment at the strategic level. Issues addressed are what is our business environment and what kind of supply chain strategies are in line with the environment?

As the customer requirements can vary among different products and even among customers, so must the supply chain designs also adequately reflect these differences. Fisher (1997) presents a clear framework based on product and product/market characteristics that is helpful in classifying the products in either innovative or functional ones. Fisher's (1997) recommends a responsive supply chain strategy for innovative products, that are characterised by short product lifecycles, large SKU variety, high contribution margins, high forecast errors, stockouts, heavy mark-downs and relatively long production lead times. After having arrived at a relevant problem formulation and when data is gathered and analysed, then follows the model construction with either specified simulation software or a general purpose programming language and validation of the model.

\section{Step 2: Evaluate solution tactics}

The next step in our approach is to evaluate different solution tactics. Ideally we can define a limited number of internally consistent scenarios. The purpose is to determine the relative efficacy of different types of solutions, e.g. increasing delivery frequency to the distribution channel has a major impact on service levels. That is, we evaluate what are the change levers we can apply to realise the supply chain strategy.

As a analysis technique this approach is scenario simulation. Guidelines for a sound simulation modelling project were already presented. Some examples can be found in Lehtonen and Holmström (1998). Regardless of whether the analyst reduces the experimental design through $\mathrm{CA}$ or the design is reduced by problem definition or by subject matter experts involved in the simulation project, the outcome should be a greatly reduced experimental design where a few internally consistent scenarios can be compared by using simulation modelling. 


\section{Step 3. Find detailed solution}

Finally, we increase the level of detail, combining different solution tactics to arrive at a concrete solution for the company. For this we need to apply more elaborate experimental design methods or search algorithms that accommodate several variables in a stochastic, correlated errors environment must be used. A common approach explained by Law and Kelton (1991) is to use design of experiments techniques. An example of such an approach and be found in Lehtonen (1999). Lehtonen (1999) uses a simulation model for testing the performance of different order penetration point locations under several variables, where a given set of variables defines one supply chain situation. From a company perspective, some variables are environmental (low vrs. high demand,) and some are decisional (production cycle length) and yet some can, depending on the time perspective and company situation, be both (shipping frequency, product variety, demand variability, shipping time). This approach is applicable in both analysis of competitor supply chains and own supply chain faced with several open decisional variables

\section{CASE BASIC MATERIALS}

The approach is illustrated with a real-life case example. The case illustrates how to evaluate the need to change supply chain strategy, test the tactical solution scenarios and detailed operational solutions by applying the three-step supply chain development approach.

The case company operates a large basic materials production plant. The production environment is in the capital intensive process industry with traditionally limited product ranges, long lead times and large batch sizes. The production layout consisted of two departments and a decoupling inventory between them. The main markets in Europe accounted for around $70 \%$ of the sales.

The supply chain strategy analysis (step 1) identified as the key problem the increased customer requirement for shorter, more reliable, order delivery lead times. The product of the company is defined by its physical dimensions and the packaging. Just the number of stock keeping units (SKU) from the different size combinations required by the customers would run into the hundreds. However, since the wholesaler customers of the company also market the product under their own brand names, the number of SKUs run up into the thousands when also the packaging is considered.

The customer requirement for shorter delivery lead-times is due to the very large number of end product variants kept in stock. In this situation a reduction in delivery lead-times and improved reliability can be immediately translated into substantial inventory savings and service improvements. It was clearly not possible to meet the market requirement for increased product differentiation, without 
reconsidering the traditional efficiency-based supply chain strategy of the case company.

The next step - step 2 - is to evaluate the different solution tactics. A desirable solution would have been to integrate directly with the inventory management processes of the major wholesalers, and move to a replenishment mode of operation. However, in the short term this was not feasible due to a lack of collaboration between the players in the supply chain. A decision was made to use simulation to determine what changes were necessary in order to continue competing with the current demand-supply chain configuration.

The basic design choices considered were to reduce the production cycle, to increase the commonality of components used, and reduce lot sizes in the packaging department.

In table 1 we see the effects of the basic design choices of halving the production cycle (cycle halving), increasing commonality by moving from five to three basic platforms (3 std.), and reduction of production lot size in the packaging department (Lot size halving) to performance measures of order backlog, decoupling inventory size and both average and $90 \%$-point delivery time.

Table 1 Solution scenarios for supply chain responsiveness increase

\begin{tabular}{llll}
\multicolumn{2}{l}{ Performance measure Cycle halving } & 3 std. & Lot size halving \\
\hline Order Backlog & $0 \%$ & $-40 \%$ & $-34 \%$ \\
Decoupling inventory & $-24 \%$ & $-15 \%$ & $0 \%$ \\
Average delivery & $-1 \%$ & $-26 \%$ & $-36 \%$ \\
Delivery time $90 \%$ & $-11 \%$ & $-22 \%$ & $-36 \%$ \\
\hline
\end{tabular}

The third step was to identify and compare the possible supply chain changes needed to support a more responsive strategy without closer integration with customer demand processes. The magnitude of the effect of design options depended also on other variables that were held constant in the Table 1. However, sensitivity analyses were performed by changing utilisation (i.e. market situation), decoupling inventory service level and maximum order size delivered from decoupling inventory. Of the design choices production cycle length halving has the largest effect on decoupling inventory but its effect on delivery is very small. By applying a suitable combination of an increase of communality and reduced lot sizes it was possible to meet the requirements for fast deliveries from the decoupling inventory, whose size could be controlled by adjusting the production cycle accordingly. The key to achieving an applicable responsive supply chain 
strategy was therefore a decoupling inventory accompanied by a combination of supply chain design changes.

\section{INCORPORATING SIMULATION IN THE DAY TO DAY OPERATIONS}

The knowledge management perspective is seldom discussed in-depth in connection with simulation modelling. From the knowledge management point of view, also supply chain development time perspective has a decisive influence on the applicability and on the way simulation can be used. From the knowledge management point of view, the integration of a simulation model to ERP systems is the key to make it part of the day to day operational decision making. Too often simulation models remain one-time, throw-away analysis tools - or at least the full potential is not reached.

Integration to the operational level is always an issue. The knowledge management problem is straightforward, while the transactional data (customer orders, buffer sizes, material receipts) needs to organised. Along with the increased use of ERP systems in the companies, the data is becoming available. In the SAP $\mathrm{R} / 3$ environment the integration solution is to build query links from the SAP system, or creating statistical update links.

In responsive supply chains the knowledge management issue at tactical level is how to create new scenarios over time. Organising the knowledge management at the tactical level simulations becomes a key issue in responsive supply chains. For tactical simulation there is no immediate need for input form simulation platform to ERP system because outputs are more like buffering needs and capacity requirements that are not readily transferable.

A modeller must make decisions concerning how to implement the model elements, like operators, operator skill classes, machines, machine capacities, buffer capacities, transportation equipment, products, routings, set-ups, manufacturing times, transport times, lot sizes, scheduling rules ect. Some can be made updateable but usually not everything, at least without having to be able to use some simulation language or commercial simulation package. By increasing the integration, there are two considerations

- Increased model building effort

- Have there been made the correct decisions on what are issues of future interest and changes. If an issue arises that has not been expected in the model building, then the specific issue is not updateable without coding.

Finding the appropriate level of integration means balancing between increased model building effort and the future savings in the ability to re-perform the analyses. An informed decision requires estimates on the increase of building effort and the frequency of model reuse. As the responsive chains cope with dynamic environments of the innovative products, there is a recurring need for model reuse. Decisions concerning the model modification requirements must be 
considered front-end in the early phases of the simulation project, prior to model building.

\section{CONCLUSIONS}

The answer to the question: "How can simulation help in supply chain development?" is twofold.

Firstly, simulation is a tool for evaluating and finding operative solutions in situations where the company needs to reconsider its supply chain strategy. Here, it is critical to recognise that for simulation to be effective it needs to be supported by a systematic data gathering and problem definition approach. In our experience Controllability Analysis is a useful tool for this task. For evaluating solution tactics the scenario simulation approach is recommended.

Secondly, the development of standardised and integrated transaction processing systems, such as SAP R/3, is opening up new opportunities to drive simulation models with operational data. The impact of using simulation for operational decision making is substantial in the supply chain management area. The main area of application is 'what-if' analysis in production and distribution decision making.

From the knowledge management perspective it is tentatively concluded that the benefits of integration to ERP systems are dependent on the supply chain strategy, with increasing importance in responsive chains. The knowledge management issues need to be considered front-end in the simulation model building. Informed decisions require estimates of model reuse frequency and increased efforts accountable to integration.

\section{REFERENCES}

Eloranta, E., and Räisänen, J. (1984) A method for the design of production management systems, in: Production Management Systems: Strategies and Tools for Design, (ed. Hübner H.), IFIP conference 1984, Elsevier.

Fisher, M., Hamond, Obmeyer, Raman (1994), Making supply meet demand in an uncertain world, Harvard Business Review, May-June, Vol 72, No 3, pp. 8393

Fisher, M. (1997) What is the right supply chain for your product, Harward Business Review, March-April, 105-116.

Hoover, S. and Perry, R. (1989) Simulation - A problem-solving approach, Addison-Wesley, USA

Johnsson, M, (1992) Discrete Event Simulation - An Evaluation Tool for Logistic Systems, Lund Institute of Technology, Lund, Sweden.

Law, A. and Kelton, D.(1991) Simulation modelling and analysis, McGraw-Hill, New York. 
Lehtonen, J-M and Holmström, J. (1998) Is just-in-time applicable in paper industry logistics?, Supply Chain Management: An International Journal, Vol. 3, no. 1, 21-32.

Lehtonen, J-M and Seppälä, U. (1997) A methodology for data gathering and analysis in a logistics simulation project, Integrated Manufacturing Systems, Vol. 8 no. 5-6, 351-358.

Lehtonen, J-M. (1999) Choice of Order Penetration Point in the Nordic Paper Industry Environment, Paper and Timber, forthcoming.

Naylor, T., Balintfy, J., Burdick, D. and Kong, C., 1966, Computer Simulation Techniques, John Wiley, U.S.A.

Robinson, S. (1994) Successful simulation: a practical approach to simulation projects, McGraw-Hill, London.

Waller, M., Johnson, M. and Davis, T. (1999) Vendor-Managed Inventory in the Retail Supply Chain, Journal of Business Logistics, Vol. 20, No. 1, pp. 183203

\section{BIOGRAPHY}

Tech. Lic. Juha-Matti Lehtonen received his M. Sc. in 1993 and Tech. Lic. degree in 1996 and has been working in various research projects at the TAI Research Centre in Helsinki University of Technology. His research interest areas are logistics, supply chain, production control and applying simulation to as a modelling tool for these areas.

Jan Holmström received his Ph.D. in 1995 from Helsinki University of Technology. After that, he has worked as an IT specialist in a large multinational consumer goods manufacturer and in a large multinational consultancy. 